\title{
Intoxicação por nitratos e nitritos em bovinos por ingestão de Echinochloa polystachya (capim-mandante) e Pennisetum purpureum (capim-elefante) no sertão da Paraíba ${ }^{1}$
}

\author{
Rosane M.T. Medeiros ${ }^{2}$, Franklin Riet-Correa², Ivon M. Tabosa ${ }^{2}$, Zoélio A. Silva², \\ Rossemberg C. Barbosa ${ }^{2}$, Ana Valéria M.S. Marques ${ }^{2}$ e Francisco R.B. Nogueira ${ }^{2}$
}

\begin{abstract}
Medeiros R.M.T., Riet-Correa F., Tabosa I.M., Silva Z.A., Barbosa R.C., Marques A.V.M.S. \& Nogueira F.R.B. 2003. [Nitrate and nitrite poisoning in cattle caused by the ingestion of Echinochloa polystachya and Pennisetum purpureum in the semiarid region of the state of Paraíba. | Intoxicação por nitratos e nitritos em bovinos por ingestão de Echinochloa polystachya (capim-mandante) e Pennisetum purpureum (capim-elefante) no sertão da Paraíba. Pesquisa Veterinária Brasileira 23(1):17-20. Centro de Saúde e Tecnologia Rural, Universidade Federal de Campina Grande, Campus de Patos, 58700-000 Patos, PB, Brazil. E-mail: rmtmed@cstr.ufpb.br

Three outbreaks of nitrate poisoning are reported from the semiarid region of the state of Paraíba, northeastern Brazil. One outbreak caused by Echinochloa polystachya (capim-mandante) and two others caused by Pennisetum purpureum (capim-elefante) occurred at the end of the dry season, after the first rains. In one of the outbreaks caused by Pennisetum purpureum part of the pasture had been fertilized with cattle manure. Five out of 11 cattle died on one farm, 27 out of 81 on another, and 3 out of 9 on a third one. Clinical signs were anorexia, respiratory distress, teeth grinding, depression or hyperexitability, tremors, abdominal contractions, salivation, nasal discharge, uncoordinated gait, cyanosis, and finally recumbency. Nitrates and nitrites in the blood of affected cattle and pastures were determined by the diphenylamine test. It is suggested that the main reason for nitrate accumulation in the grasses was the prolonged draught followed by rain. In one of the outbreaks caused by Pennisetum purpureum, another reason was probably the fertilization of the soil with cattle manure.
\end{abstract}

INDEX TERMS: Nitrate poisoning, Echinochloa polystachya, Pennisetum purpureum, capim-elefante, capimmandante.

RESUMO .- Descrevem-se três surtos de intoxicação por nitratos e nitritos em bovinos na região semi-árida do estado da Paraíba, nordeste do Brasil. O primeiro surto foi causado por Echinochloa polystachya (capim-mandante) e os demais por Pennisetum purpureum (capim-elefante) e ocorreram após um período prolongado de seca, após o início das primeiras chuvas. Em um dos surtos causado por Pennisetum purpureum, uma parte da área onde estava o pasto que continha níveis altos de nitratos havia sido fertilizada com esterco de bovi-

\footnotetext{
${ }^{1}$ Aceito para publicação em 16 de dezembro de 2002.

Trabalho financiado pelo Programa de Apoio a Núcleos de Excelência (PRONEX), Processo CNPq $n^{\circ} 7697102600$.

${ }^{2}$ Centro de Saúde e Tecnologia Rural, Universidade Federal de Campina Grande, Campus de Patos, Jatobá, Paraíba, PB 58700-000, Brasil. E-mail: rmtmed@cstr.ufpb.br
}

no. No primeiro surto morreram 5 bovinos de um total de 11 , no segundo morreram 21 de um total de 81 e no terceiro morreram 3 de um total de 19 bovinos. Os sinais clínicos se caracterizaram por anorexia, dispnéia, ranger de dentes, depressão ou hiperexitabilidade, tremores, contrações abdominais, salivação, corrimento nasal, andar cambaleante, mucosas cianóticas e, finalmente, decúbito. A presença de nitratos e nitritos foi detectada no sangue dos animais e nos pastos por meio da prova de difenilamina. Parece que o principal fator que determinou a concentração de altos níveis de nitratos nas plantas foi a ocorrência de chuvas depois de um longo período de seca. Outro fator importante no surto causado por Pennisetum purpureum foi a fertilização do solo com esterco.

TERMOS DE INDEXAÇÃO: Intoxicação por nitratos, Echinochloa polystachya, Pennisetum purpureum, capim-elefante, capim-mandante. 


\section{INTRODUÇÃO}

Em ruminantes que consomem plantas com alto conteúdo de nitratos as bactérias do rúmen reduzem estes compostos em nitritos. Os nitritos uma vez absorvidos oxidam o íon ferro da hemoglobina transformando-a em meta-hemoglobina. Como a meta-hemoglobina não reage com o oxigênio ocorre anóxia celular. Com níveis de 30 a $40 \%$ de meta-hemoglobina ocorrem sinais clínicos e níveis de 80 a $90 \%$ causam a morte. A susceptibilidade das diferentes espécies depende da capacidade de transformar nitratos em nitritos. A espécie mais sensível é a suína, seguida da bovina, ovina e eqüina (Cheeke 1998, Radostits et al. 2000).

Mais de 90 espécies de plantas, incluindo diversas gramíneas, podem causar intoxicação por nitratos e nitritos. Alguns dos fatores que determinam altas concentrações de nitratos nas plantas incluem: fertilização com adubos nitrogenados ou matéria orgânica de origem animal; algumas características do solo, tais como areação, temperatura, acidez, deficiência de fósforo, enxofre ou molibdênio; rápido crescimento das plantas quando ocorrem chuvas após períodos de seca; e tratamento das pastagens com herbicidas $(2,4-$ D e derivados) (Riet-Alvariza 1993, Cheeke 1998, Radostits et al. 2000).

O objetivo deste trabalho é descrever três surtos de intoxicação por nitratos e nitritos em bovinos no estado de Paraíba, região Nordeste do Brasil.

\section{MATERIAL E MÉTODOS}

Os dados epidemiológicos e clínicos foram obtidos mediante visitas as propriedades e consultas aos proprietários. As três propriedades onde ocorreram os surtos estão localizadas na região semi-árida (sertão) do estado da Paraíba. A Propriedade 1, no distrito de Santa Gertrudes, município de Patos, a Propriedade 2 no município de São José de Lagoa Tapada e a Propriedade 3 no município de Patos.

Em todos os estabelecimentos amostras de pasto foram coletadas e enviadas para o setor de agrostologia da Universidade Federal de Campina Grande, Campus de Patos, para identificação. Em amostras de capim procedentes das três propriedades foram realizadas a prova do papel picro-sódico para verificar a presença de cianeto (Tokarnia et al. 2000) e de difenilamina para determinar a presença de nitratos e nitritos (Riet-Alvariza 1993). Esta última prova foi realizada, também, em sangue colhido da veia jugular de dois animais doentes no primeiro surto e um no terceiro surto. Para a realização do teste em pastagens foram preparadas duas soluções: uma solução (A) com $0,5 \mathrm{~g}$ de difenilamina em $2 \mathrm{ml}$ de água destilada, agregando-se ácido sulfúrico em quantidade suficiente para $100 \mathrm{ml}$; e uma segunda solução (B), de ácido sulfúrico a $80 \%$. As duas soluções foram mantidas em vidro de cor escura. Para a realização da prova, quantidades iguais das duas soluções foram colocadas em uma placa de Petri, agregando- se pequenos pedaços de talos da planta. A prova foi considerada positiva quando, após 2-3 minutos, observou-se uma coloração azul nas bordas dos pedaços da planta. Para a realização da prova da difenilamina no sangue, 2-3 gotas do sangue foram colocadas em uma lâmina e secadas ao ar durante 2 minutos, em seguida agregouse duas gotas de água destilada livre de nitratos, misturando-se o sangue com a água. Posteriormente foram misturadas duas ou três gotas desse material com $2-3 \mathrm{ml}$ de reativo de difenilamina (difenilamina a $1 \%$ em ácido sulfúrico). A reação foi considerada positiva quando, após 30 segundos a 2 minutos, observou-se a formação de um halo azul ao redor das gotas do material (RietAlvariza 1993).

Para o tratamento dos animais com sinais clínicos foi administrado, pela via intravenosa, $4 \mathrm{mg}$ por $\mathrm{kg}$ de peso vivo de azul de metileno em uma solução a $1 \%$, em dose única no primeiro surto e em doses repetidas diariamente por três dias na Propriedade 3.

Uma vaca do primeiro surto, duas do segundo e uma do terceiro foram necropsiadas. Fragmentos de vários órgãos foram colhidos de cada animal, processados rotineiramente para histopatologia e corados com hematoxilina-eosina.

Dados referentes a precipitação pluviométrica no município de Patos, de janeiro de 2001 a janeiro de 2002, foram obtidos junto ao Terceiro Distrito do Instituto Nacional de Meteorologia.

\section{RESULTADOS}

Nas Propriedades 1 e 2 os surtos de intoxicação por nitratos e nitritos ocorreram no final de dezembro de 2001, depois de um período prolongado de estiagem (Quadro 1), após a ocorrência das primeiras chuvas, que foram de $21,7 \mathrm{~mm}^{3}$. Na Propriedade 3 o surto ocorreu no início de janeiro de 2002.

Os surtos ocorreram após a ingestão de Echinochloa polystachya (capim-mandante) plantado em uma área próxima à rodovia BR 230 e às margens de um açude na Propriedade 1 e após a ingestão de Pennisetum purpureum (capim-elefante) nas Propriedades 2 e 3 . Na Propriedade 2 o capimelefante havia sido plantado em uma área ao lado do curral. Essa área era dividida em duas partes; na parte central o terreno havia sido adubado com esterco proveniente do curral e, segundo o proprietário, somente o capim dessa área era tóxico aos animais. Na Propriedade 3 o capim-elefante era plantado as margens do açude Jatobá em Patos.

Nas três propriedades, de um total de 111 bovinos de diferentes idades que estavam sendo alimentados com os capins com alto conteúdo de nitratos e nitritos, 43 animais foram afetados e 30 morreram. Na Propriedade 1, onze bovinos semi-confinados eram alimentados, duas vezes por dia, com o pasto cortado e picado na forrageira. Oito animais (duas vacas em ordenha, um touro, três bezerros e duas novilhas) foram afetados, 10 dias após o início da ingestão. Cinco

Quadro 1. Precipitações pluviométricas mensais ocorridas no município de Patos de janeiro de 2001 a janeiro de $2002^{\mathrm{a}}$

\begin{tabular}{ccccccccccccc}
\hline \multicolumn{10}{c}{ Mês $\left(\mathrm{mm}^{3)}\right.$} \\
\hline Jan. 2001 & Fev. & Mar. & Abr. & Mai. Jun. & Jul. & Ago. & Set. & Out. & Nov. & Dez. Jan. 2002 \\
\hline 14,4 & 7,2 & 171,2 & 168,7 & 11,4 & 81,8 & 11,2 & 0 & 6,2 & 2,6 & 0,2 & 21,7 & 380,4
\end{tabular}

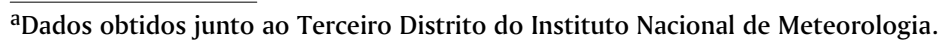


animais morreram, dois se recuperaram sem tratamento e um recuperou-se após o tratamento com azul de metileno. Na Propriedade 2, de um total de 180 bovinos, 81 eram alimentados com capim-elefante havia pelo menos, nove meses. $O$ pasto era cortado à tarde, entre 13:00 e 14:00 h, picado e administrado uma vez por dia. $\mathrm{O}$ surto ocorreu quando o pasto estava sendo cortado pela segunda vez. Os demais animais do estabelecimento se alimentavam com pasto nativo. Dos 81 bovinos alimentados com capim-elefante adoeceram sete vacas. Cinco morreram no mesmo dia e os dois restantes se recuperaram. 0 proprietário suspeitou que as mortes fossem causadas pela ingestão do capim-elefante e diminuiu a quantidade do pasto administrada. Depois de 4 dias resolveu aumentar novamente a quantidade de capim-elefante. Nesse mesmo dia adoeceram 20 bovinos e morreram 16. Segundo o produtor, a enfermidade ocorria nos animais que ingeriram o pasto cortado na área que havia sido fertilizada com esterco. Também segundo o proprietário os animais que adoeceram foram aqueles que ingeriram mais pasto. Na Propriedade 3, o capim era cortado e levado ao estabelecimento, passado na máquina e fornecido aos animais uma vez ao dia. De um total de 58 bovinos, 19 eram alimentados com capim-elefante havia pelo menos um mês. Os demais animais se alimentavam de pasto nativo. Dos 19 bovinos alimentados com capim-elefante adoeceram oito vacas. Três animais morreram, dois se recuperaram espontaneamente (sem tratamento) e três foram tratados com azul de metileno e se recuperaram.

Os sinais clínicos caracterizaram-se por dispnéia com respiração com o pescoço estendido, ranger de dentes, anorexia, apatia ou hiperexcitabilidade, tremores, contrações abdominais, salivação, corrimento nasal, andar cambaleante, mucosas cianóticas, olhar assustado, pêlos arrepiados e, finalmente, decúbito. Alguns animais apresentavam timpanismo após estarem em decúbito. 0 curso clínico variou de 2 a 9 horas e depois de estar em decúbito a morte ocorria em aproximadamente 30 minutos.

Na necropsia de um animal da Propriedade 1 realizada no dia seguinte ao da morte, foi observada abundante espuma nos brônquios e traquéia. Em consequiência do avançado estado de autólise não foi realizado estudo histológico. Nas necropsias dos animais das Propriedades 2 e 3 não foram encontradas lesões macroscópicas nem histológicas significativas.

Um bezerro do primeiro surto que apresentava sinais respiratórios graves, foi levado ao Hospital Veterinário onde foi coletado sangue para realização da prova de difenilamina, que resultou positiva para a presença de nitratos e nitritos. $\mathrm{O}$ animal foi tratado com $4 \mathrm{mg}$ de azul de metileno por $\mathrm{kg}$ de peso vivo em uma solução a $1 \%$, recuperando-se em menos de 24 horas. Outro animal que permaneceu no estabelecimento estava totalmente recuperado 6 dias após a retirada do capim-mandante da alimentação. Foi realizada a prova de difenilamina em uma amostra de capim mandante que resultou fortemente positiva para a presença de nitratos e nitritos. Na mesma amostra foi realizada a determinação de ácido cianídrico mediante a prova do papel picrosódico que resul- tou negativa. Três dias após a recuperação do animal que permaneceu no estabelecimento, o proprietário voltou a administrar o capim-mandante aos animais sobreviventes. Um bezerro apresentou um quadro semelhante aos anteriores. Foi tratado com azul de metileno quando estava em decúbito porém morreu algumas horas depois. Neste animal a prova de difenilamina no sangue também resultou positiva.

Na Propriedade 2 não foi realizada a prova de difenilamina no sangue dos animais e também não foram realizados tratamentos, uma vez que o surto foi diagnosticado após a morte dos animais. Foi realizada a prova de difenilamina nas amostras do capim-elefante da área fertilizada e da área não fertilizada. As amostras da área fertilizada com adubo orgânico foram fortemente positivas e enquanto que nas da área não fertilizada foram levemente positivas. Todas as amostras foram negativas para ácido cianídrico.

Na Propriedade 3 foi realizada a prova de difenilamina no sangue de um animal doente sendo o resultado fortemente positivo. Todos os animais doentes foram tratados com azul de metileno, diariamente, por 3 dias e se recuperaram. A prova de difenilamina foi também realizada em amostras do capim-elefante resultando fortemente positiva.

\section{DISCUSSÃO}

Os dados epidemiológicos que indicavam que a enfermidade estava associada ao consumo de forragem, os sinais clínicos característicos, a resposta ao tratamento com azul de metileno e a positividade da prova da difenilamina, tanto no sangue dos animais afetados, quanto nas pastagens, confirmam o diagnóstico de intoxicação por nitratos e nitritos. Esta é a primeira comprovação de intoxicação por nitratos e nitritos em bovinos no Brasil. Anteriormente foram levantadas suspeitas da ocorrência da enfermidade em diversas regiões do Brasil em casos que posteriormente foram diagnosticados como botulismo (Tokarnia et al. 2000). No Rio Grande do Sul foi realizado um diagnóstico presuntivo da intoxicação em bovinos que tinham sido introduzidos numa área invadida por Amaranthus sp (Schild et al. 1996).

Echinochloa polystachya e Pennisetum purpureum são gramíneas comumente utilizadas como forrageiras na região nordeste do Brasil. Os dois gêneros tem sido responsabilizados por surtos de intoxicação por nitratos e nitritos em outros países (Radostits et al. 2000). Nos dois surtos descritos neste trabalho, é evidente que o fator que determinou a presença de níveis tóxicos de nitratos nas plantas foi a ocorrência de chuvas depois de um prolongado período de seca. É bem conhecido que quando chove após períodos de seca as plantas crescem rapidamente absorvendo níveis tóxicos de nitratos (Riet-Alvariza 1993, Cheeke 1998, Radostits et al. 2000). No primeiro surto causado por Pennisetum purpureum é evidente que, além do fator climático, outro fator importante que determinou a alta concentração de nitratos nas plantas foi a fertilização do solo com esterco. Isto foi evidenciado pelo fato de que somente o pasto da parte que havia sido fertilizada causou intoxicação e era fortemente positiva a prova de difenilamina. Outro fator que pode ter favorecido a ocorrência da enfermidade é o consumo 
rápido do pasto por parte dos animais, devido este ser cortado e administrado duas vezes ao dia no caso do capim-mandante ou uma vez ao dia nos dois surtos causados por capimelefante.

A região semi-árida do Nordeste do Brasil, que ocupa 13,52\% da área do país, se caracteriza por períodos de seca prolongada com poucas chuvas, concentradas em um período curto do ano. Considerando que essas condições favorecem a acumulação de nitratos nas plantas, é evidente a probabilidade de que a intoxicação por nitratos e nitritos seja freqüente na região causando perdas econômicas importantes. $\mathrm{O}$ conhecimento desta intoxicação por parte dos veterinários da região poderá contribuir para o conhecimento da enfermidade e a diminuição das eventuais perdas econômicas.

\section{REFERÊNCIAS}

Cheeke P.R. 1998. Natural Toxicants in Feeds, Forages, and Poisonous Plants. $2^{\text {nd }}$ ed. Interstate Publishers, Danville. 479p.

Radostits O.M., Gay C.C., Blood D.C. \& Hinchcliff K.W. 2000. Veterinary Medicine. $9^{\text {th }}$ ed. W. B. Saunders, London. 1881p.

Riet Alvariza F. 1993. Intoxicación por nitratos y nitritos, p. 291-297. In: RietCorrea F., Méndez M.C. \& Schild A.L. (ed.) Intoxicações por Plantas e Micotoxicoses em Animais Domésticos. Editorial Agropecuaria Hemisferio Sur, Montevideo.

Schild A.L., Riet-Correa F., Ruas J.L., Rivero G.R.C., Fernandes C.G., Motta A., Mendez M.C., Soares M. \& Timm C.D. 1996. Doenças diagnosticadas pelo Laboratório Regional de Diagnóstico no ano 1995. Boletim do Laboratório Regional de Diagnóstico $\mathrm{n}^{\circ}$ 16, Pelotas, p. 9-38.

Tokarnia C.H., Döbereiner J. \& Peixoto P.V. 2000. Plantas Tóxicas do Brasil. Editora Helianthus, Rio de Janeiro. 310p. 